\title{
PENERAPAN TEKNOLOGI BAGI ORANGTUA UNTUK KONTROL DAN PEMANTAUAN TUMBUH KEMBANG BALITA DENGAN APLIKASI ANDROID MOBILEPHONE
}

\author{
Walhidayat $^{\text {1), }}$ Bayu Febriadi'), Mariza Devega ${ }^{2)}$ \\ ${ }^{1,2)}$ Prodi Sistem Informasi Fakultas Ilmu Komputer Universitas Lancang Kuning \\ Email : walhidayat@unilak.ac.id; bayufebriadi@unilak.ac.id; marizadevega@unilak.ac.id
}

\begin{abstract}
ABSTRAK
Pelaksanaan pengabdian kepada masyarakat yang dilakukan oleh tim pelaksana dari fakultas ilmu komputer ini, antara lain merupakan suatu kegiatan untuk mensosialisasikan berbagai manfaat keberadaan teknologi informasi untuk menunjang keperluan masyarakat sehari hari, dengan semakin berdampaknya pengaruh Internet of Things (IoT). Dalam hal ini tim pengabdian melihat adanya kerentanan bagi ibu - ibu muda dalam pola pengasuhan Balita nya sendiri, cara pengontrolan kebiasaan asuh dan pemantauan tumbuh kembang bayi dapat dilakukan dengan memanfaatkan perangkat smartphone berbasis android yang dimiliki oleh ibu tersebut. Maka disini peran tim pengabdian untuk memperkenalkan, sosialisasi dan pelatihan aplikasi teknologi informasi, agar mereka dapat melihat suatu kebutuhan dan peluang dapat dimanfaatkan dengan menyesuaikan dari kebiasaan sehari - hari menggunakan smartphone menjadi suatu aktifitas kegiatan untuk memantau tumbuh kembang balita dengan cara yang menyenangkan. Kegiatan pengabdian kepada masyarakat ini dilaksanakan dilingkungan Puskesmas umban sari, yang berada di kecamatan Rumbai, lokasi Posyandu yang dituju adalah Posyandu di kelurahan Srimeranti dan Umbansari, dengan periode waktu pelaksanaan pada bulan April sampai dengan bulan Juni 2019. Adapun cara yang di lakukan dalam kegiatan Iptek bagi Masyarakat ini adalah: dengan memilih aplikasi android yang tepat guna, mensosialisasikan, membarikan pelatihan cara menggunakan dan melakukan pendampingan keluhan tentang aplikasi tumbuh kembang Balita. Dalam hal ini bagi akademisi dapat memanfaatkan peluang ini agar lebih dekat dan memahami bagaimana membuat suatu aplikasi yang dapat di pergunakan dan di pasarkan.
\end{abstract}

Kata kunci: aplikasi kontrol tumbuh balita, pemanfaatan android

\section{ABSTRACT}

The implementation of community service carried out by the implementing team from the computer science faculty, among others, is an activity to socialize the various benefits of the existence of information technology to support the daily needs of society, with the increasingly impact of the influence of the Internet of Things (IoT). In this case, the dedication team saw the vulnerability of young mothers in the pattern of their own foster care, how to control foster habits and monitor the growth of babies can be done by utilizing an Android-based smartphone device owned by the mother. So here the role of the dedication team is to introduce, socialize and train information technology applications, so that they can see a need and opportunity can be utilized by adjusting to the daily habits of using a smartphone to be an activity activity to monitor toddlers' growth in a fun way. The community service activities are carried out in the Umbas Sari Community Health Center, which is located in the Rumbai sub-district, the location of the Posyandu that is being targeted is the Posyandu in the Srimeranti and Umbansari villages, with a period of implementation from April to June 2019. Science and Technology for the Community is: by choosing the right android application, socializing, developing training on how to use and mentoring complaints about the application of Toddler development. And in this case for academics can take advantage of this opportunity to get closer and understand how to make an application that can be used and marketed.

Key words: application for growing toddler control, utilization of android 


\section{PENDAHULUAN}

Tahapan perkembangan pertumbuhan fisik dan mental anak pada usia 0 sampai dengan usia 5 tahun merupakan periode emas, pada masa - masa tersebut anak balita memiliki perubahan seiring waktu berlalu. Secara umum tumbuh kembang anak terbagi menjadi dua (2). Tumbuh (growth) merupakan perubahan yang dapat di ukur dan kembang (development) merupakan bertambahnya kemampuan struktur bagian fungsi tubuh yang lebih kompleks (doyle, Daniel. 2012). Pada sebagian kasus tumbuh kembang bayi tidak dapat mencapai ukuran sesuai standar yang ada (Buku kesehatan ibu dan anak, Kemenkes RI, 2015), dimana pada beberapa kasus tumbuh kembang anak balita tersebut belum tercapai sesuai dengan periode masanya, seperti diantaranya balita belum dapat memegang pensil pada usia 2 tahun, tinggi yang tidak sesuai dangan range standar. Beberapa permasalahan tersebut dapat di antisipasi dengan tidakan aktif orang tua untuk melakukan control dan terapi terhadap balita kesayangannya (kompas health and lifestyle, 17 sep 2015).

Pada pembahasan ini yang di tekankan bukan hanya tentang bagai mana mencapai tahapan perkembangan optimal pada periode emas tersebut, namun di lain sisi fitur dari aplikasi BabyTime ${ }^{\circledR}$ dapat memberikan beberapa jenis terapi sehari - hari unutk Balita membantu orang tua mengurus Balitanya secara teratur dan terlaksana. dengan seiring berkembangnya pencapaian lintas keilmuan oleh penggiat teknologi, memungkinkan kita untuk menggabung manfaatkan revolusi 4.0 dengan berdampaknya pengaruh IoT (Internet of Things) dapat membantu orang tua dalam memantau dan mengontrol tahapan tumbuh kembang balita melalui media aplikasi yang dapat di-aplikasikan pada perangkat smartphone yang "digunakan setiap waktu".

Memang untuk sosialisasi bagaimana memanfaatkan aplikasi tumbuh kembang bayi pada gadget yang di miliki oleh mama / bunda sudah dilakukan oleh praktisi atau akademisi sebelumnya, namun dengan seiringnya perkembangan analisis kebutuhan dan layanan yang disertakan oleh aplikasi tersebut pada saat ini aplikasi android sudah semakin lengkap untuk memenuhi kebutuhan pemantauan dan kontrol tumbuh kembang Balita. Dalam hal ini kami sebagai tim pengabdian Ipteks kepada masyarakat pada institusi Fasilkom Universitas Lancang Kuning, menyampaikan alternatif solusi yang terlengkap bagaimana melakukan control kebiasaan - kebiasaan yang baik terapi pada balita oleh orang tua dan pemantauan tumbuh kembang balita dengan aplikasi BabyCare (C) berbasis android.

Dengan harapan melalui kegiatan ini keahlian / kemampuan yang di miliki oleh tim akademis dalam mempersiapkan rancangan aplikasi lebih tepat guna dan dapat memanusiakan teknologi untuk kebutuhan sehari - hari.

Permasalahan mitra:

a. Belum lengkapnya pengetahuan secara meyeluruh tentang standar tumbuh kembang bayi sesuai dengan rujukan yang ada.

b. Bagaimana rutinitas merawat bayi dapat di lakukan secara teratur dan terencana

c. Belum adanya sosialisasi pemanfaatan aplikasi berbasis android untuk pemantauan tumbuh kembang Balita.

Solusi yang ditawarkan : memberikan sosialisasi dan pelatihan secara bertahap, menyeluruh, dan terstruktur pada orang tua yang ikut dalam memamfaatkan layanan Posyandu. 
Target pengabdian kepada masyarakat ini akan menyasar orang tua, khususnya ibu - ibu yang memanfaatkan posyandu kelurahan untuk pengontrolan anak Balita di kelurahan Rumbai pada RT/RW 01/05, Tegal Sari, dan RW 13 Kartika Sari

\section{TINJAUAN PUSTAKA}

Kegiatan Ipteks bagi Masyarakat ini diambil dengan rujukan beberapa sumber yang sudah disebutkan di dalam referensi, dimana tim pengabdian mengambil data kesenjangan antara pemahaman orang tua dalam tatacara pola pengasuhan bayi khususnya orangtua yang masih baru memiliki keturunan. Dan tim peneliti menghubungkan dengan akan dampak dan pengaruh dari gawai terhadap kebiasaan pola hidup.

\section{METODE PELAKSANAAN}

Kegiatan Pengabdian Kepada Masyarakat ini dilaksanakan di Posyandu Kelurahan Sri Meranti, dab di Posyandu J1. Tegal Sari Ujung. dengan metode seminar, tanya jawab, praktek dan evaluasi pencapaian target melalui kuisioner dan tugas. Pelatihan dilakukan selama satu hari dimana peserta akan mendapatkan modul ajar untuk pelatihan.

Metode seminar dan tatap muka diberikan saat pemberian materi dengan menggunakan slide persentasi dan handout materi. Pada awal pertemuan para orangtua yang memiliki Balita akan diberikan kuisioner tentang tingkat pemahaman materi topik sebelum melakukan pelatihan.

Pada akhir dari acara diberikan kuisioner evaluasi melihat tingkat pemahaman kepada materi dari pembicara. Metode evaluasi pencapaian target dilakukan pada awal dan akhir kegiatan. Hal ini untuk mengetahui tingkat pengetahuan peserta dan menerima masukan untuk perbaikan pada kegiatan kegiatan berikutnya. Pada sesi akhir dari pelatihan orang tua diminta melakukan demonstrasi bagaimana menggunakan aplikasi BabyTime secara menyeluruh. Secara rinci kegiatan pengabdian yang akan dilakukan sebagai berikut :

1. Kegiatan perkenalan

2. Pengenalan aplikasi berbasis android

3. Instalasi aplikasi BabyTime / atau yang sejenisnya

4. Memberikan Kuisoner pra - pelatihan

5. Pendalaman materi pelatihan

6. Melakukan tanya jawab

7. Pada hari berikutnya di berikan kuisoner untuk evaluasi (pasca sosialisasi dan pelatihan)

Kegiatan ini menggunakan bebarapa perangkat pendukung di antaranya adalah :

1. Perangkat komputer / laptop

2. Infocus

3. Smartphone

4. Aplikasi sosial media

\section{HASIL DAN PEMBAHASAN}

Kegiatan pengabdian / Ipteks bagi Masyarakat ini dilakukan dalam beberapa tahapan, diantaranya:

a. Melakukan sosialisasi / edukasi. tentang pentingnya kegiatan 
Berikut merupakan materi kegiatan pemaparan alasan dan edukasi mental untuk para orang tua yang memanfaatkan layanan Posyandu kelurahan, dan memiliki perangkat smartphone android.

b. Kegiatan Pelatihan

Adapun kegiatan pelatihan ini diadakan dengan memberikan arahan dan motivasi pentingnya menggunakan perangkat gawai secara bijak. Dan disini tim pelaksana pengabdian memberikan pandangan agar perangkat tersebut di install dengan aplikasi aplikasi yang bermanfaat dibandingkan dengan aplikasi social media (yang hanya untuk berselancar dan update)

c. Konsultasi

Konsultasi dilakukan peserta pelatihan khususnya orangtua balita dalam bagaimana cara menggunakan aplikasi, bagaimana melihat hasil laporan dari aplikasi. Berikut ditampilkan gambar peserta yang melakukan konsultasi langsung kepada penyuluh (tim pengabdian) selama acara berlangsung. Konsultasi penggunaan aplikasi tidak hanya terbatas selama acara berlangsung tetapi penyuluh bersedia melayani konsultasi peserta diluar waktu, yaitu denganmemberikan no kontak penyuluh jika nantinya dibutuhkan oleh ibu - ibu yang menggunakan aplikasi kontrol tumbuh kembang Balita.

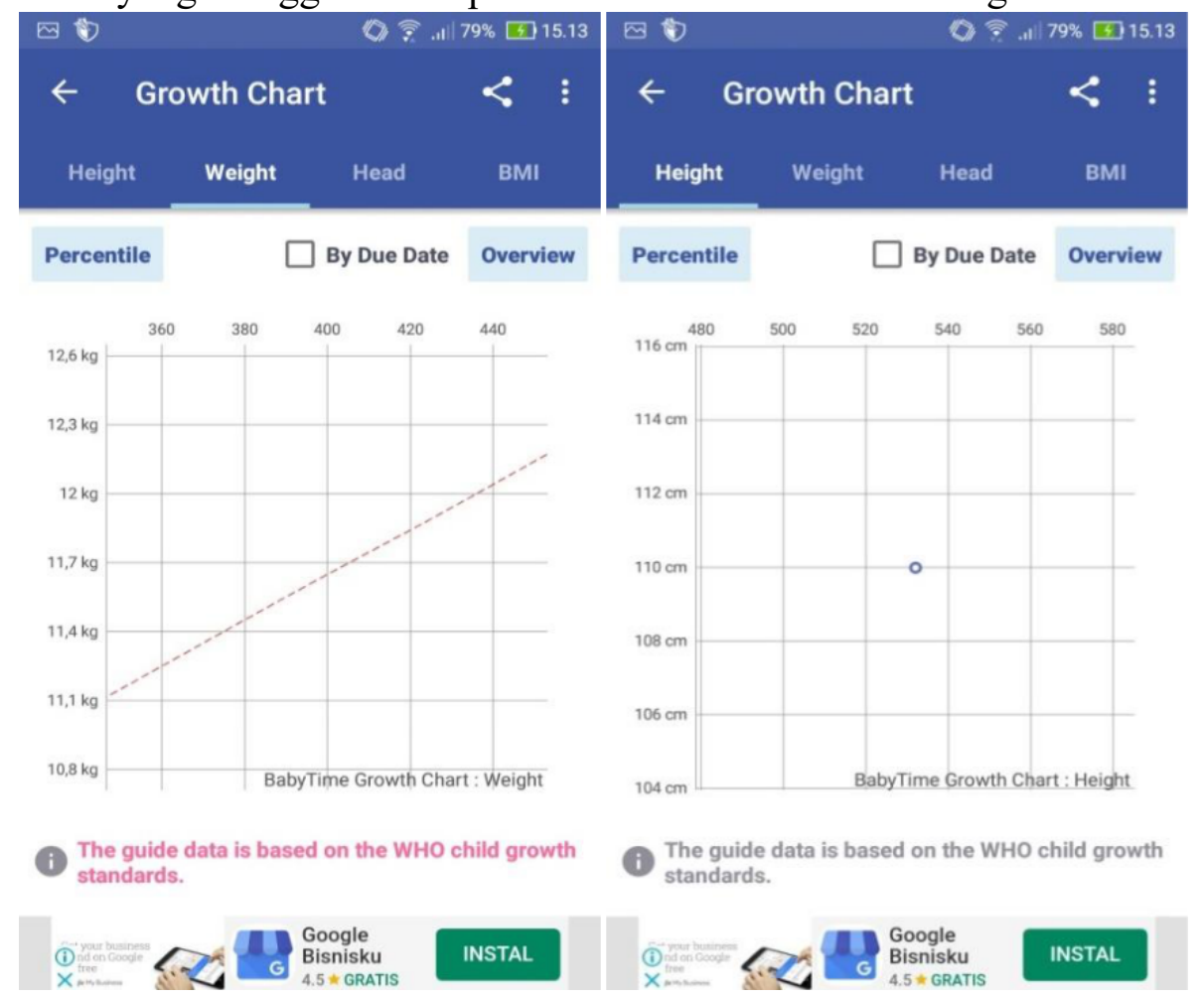

Gambar 1. Tampilan Laporan Pertumbuhan Balita 

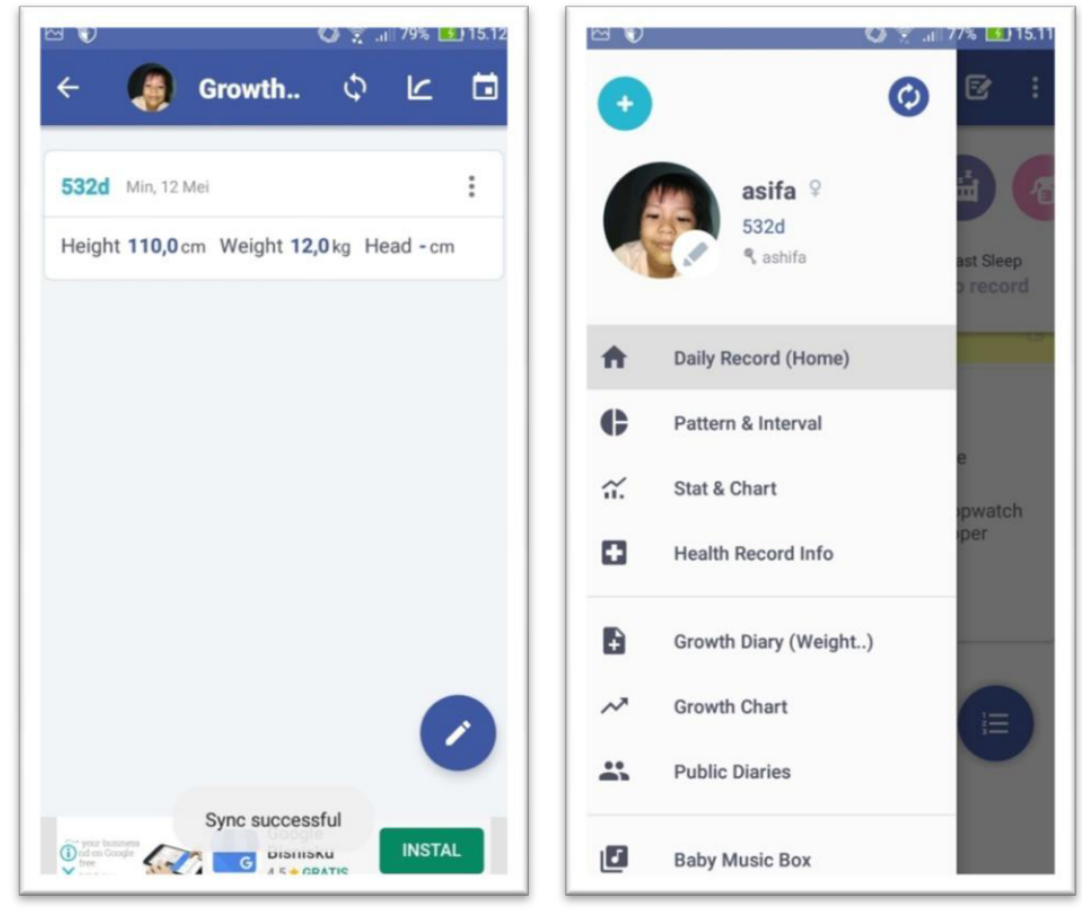

Gambar 2. Tampilan Profil Balita Aplikasi Baby Time

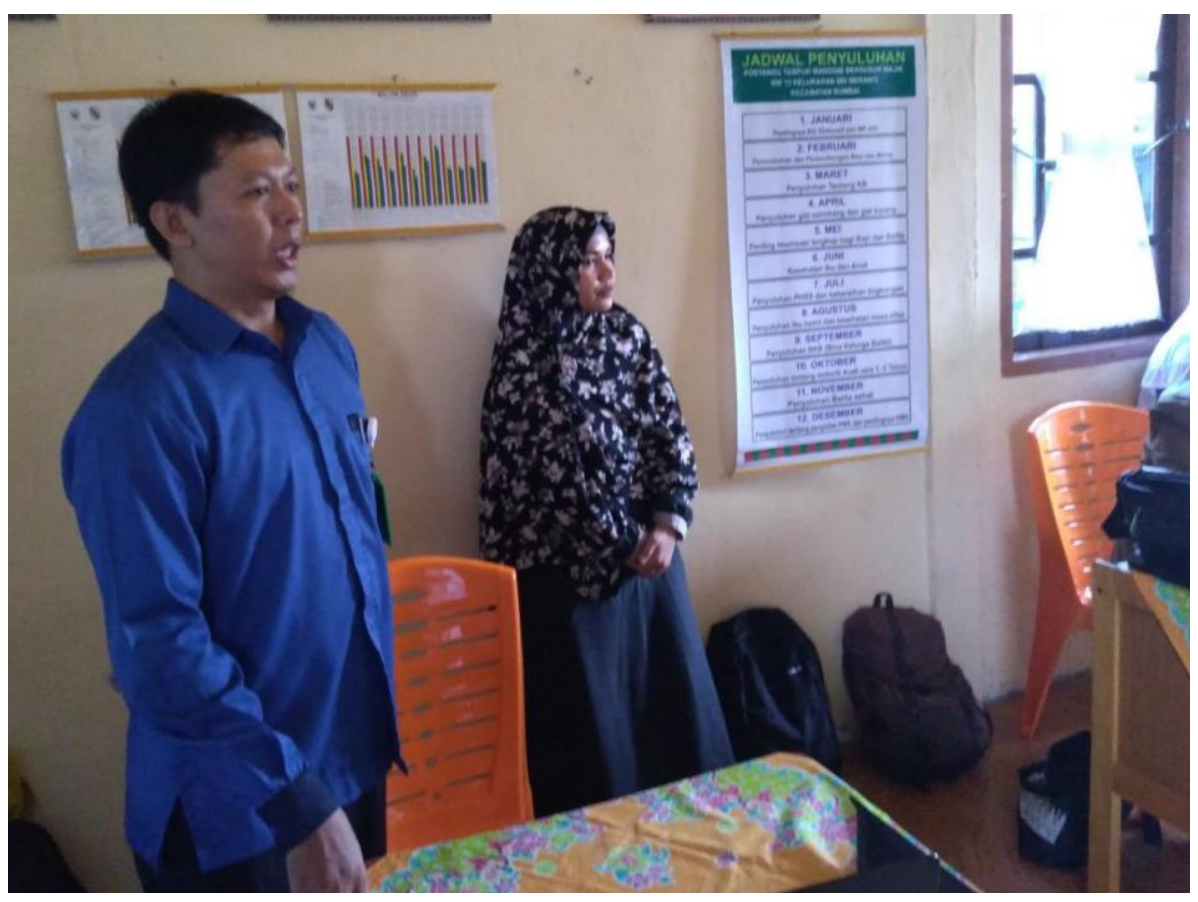

Gambar 3. Tim Penyuluh Memberikan Pelatihan 


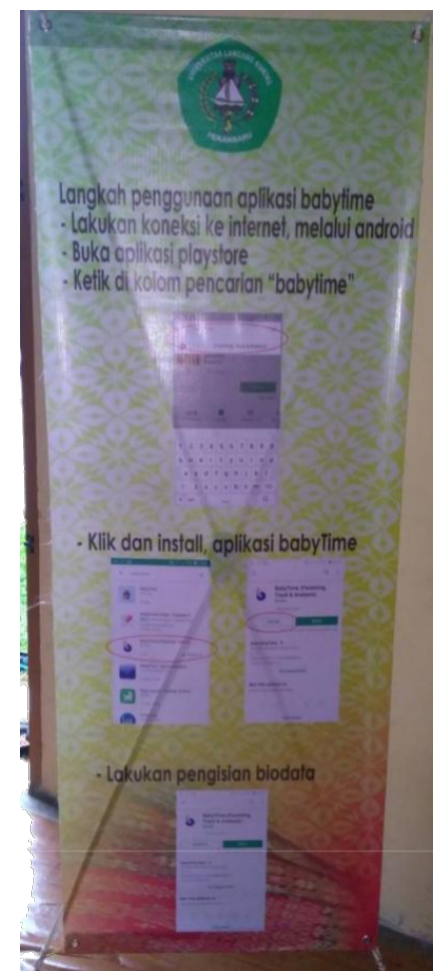

Gambar 4. Dokumentasi Dengan Peserta dan Kader Posyandu

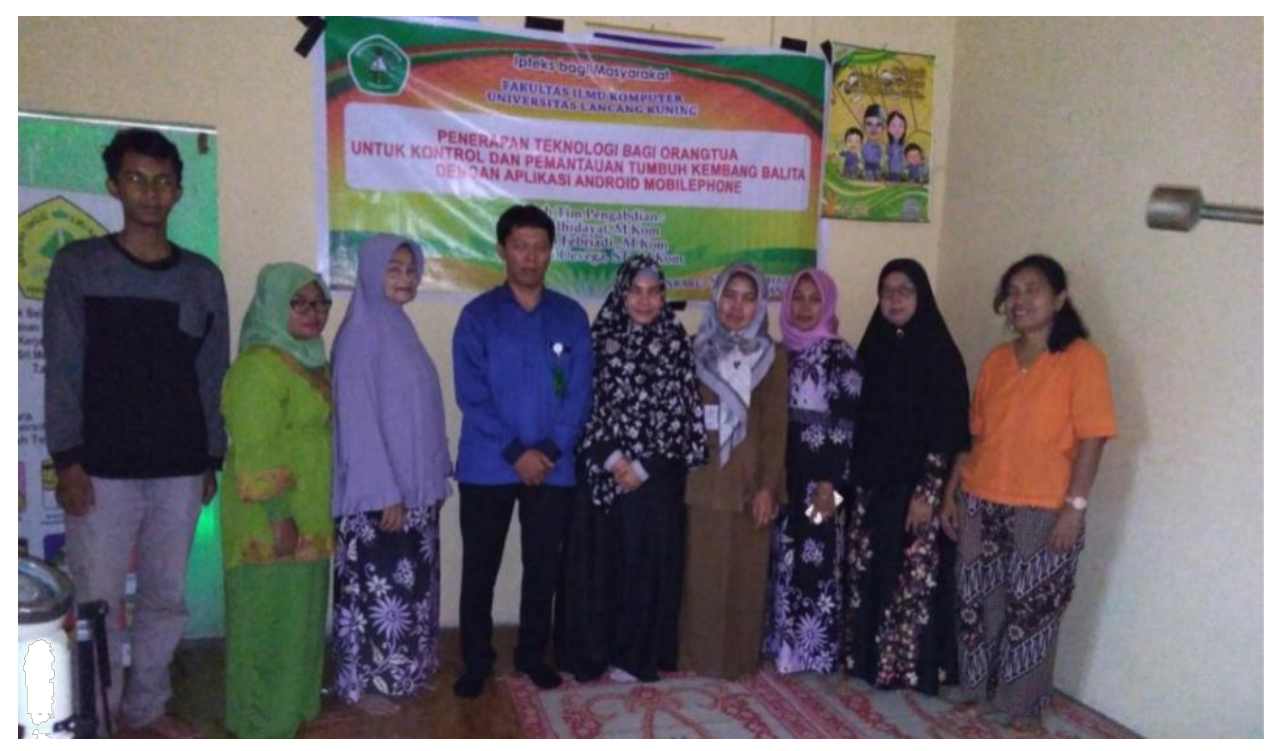

Gambar 5. Standing Banner Untuk Membantu Peserta Memahami Cara Instalasi 


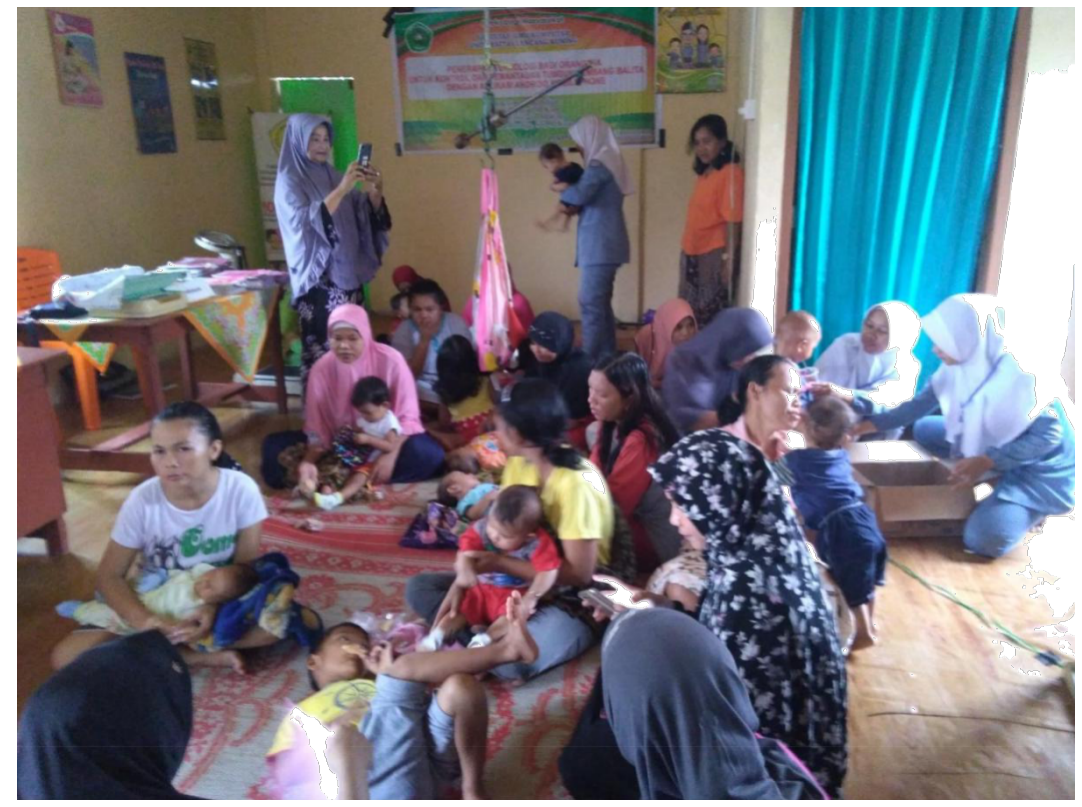

Gambar 6. Antusias Orang Tua Balita Mengikuti Kegiatan

\section{KESIMPULAN}

\section{Kesimpulan}

Berdasarkan hasil pengabdian Iptek bagi Masyarakat yang dilakukan oleh tim Dosen dan Mahasiswa Fakultas Ilmu komputer Universitas Lancang Kuning yang diadakan di beberapa Posyandu di lingkungan Umban Sari dan Sri Meranti - Rumbai dalam kurun waktu Mei - Juni 2019. Kegiatan penyuluhan dan edukasi ini sangat bermanfaat untuk peserta khususnya para orang tua Balita yang menggunakan perangkat Android, dalam memanfaatkan peranan teknologi untuk memudahkan kegiatan yang sudah dilakukan sehari - hari. Ada pergeseran pola kebiasaan yang terdampak dari kemunculan teknologi android bagi masyarakat.

Dalam hal ini tim pengabdian berhasil memberikan edukasi bagi orang tua untuk mendapatkan hasil yang baik bagi pengaruh teknologi bagi kehidupan sehari - hari, khususnya teknologi informatika dan komunikasi.

\section{Saran}

Dari pengabdian yang dilakukan oleh tim diharapkan dapat menjangkau lebih banyak posyandu - posyandu di bawah naungan puskesmas untuk lingkup Rumbai ataupun mencakup keseluruhan daerah kotamadya Pekanbaru secara umum. Hal ini sejalan dengan arahan Kepala Puskesmas Umbansari untuk kedepannya kegiatan ini lebih menyeluruh dan mendapat perhatian dari instansi terkait dan lebih bekerja sama dan bersinergi.

Dari sisi tampilan aplikasi, tim pengabdian mengharapkan dan menggalakkan mahasiswa khususnya mahasiswa Fasilkom Universitas Lancang Kuning agar dapat menciptakan aplikasi serupa, yaitu aplikasi kontrol dan tumbu kembang Blaita yang berbahasa Indonesia. Agar kedepannya aplikasi ini lebih dapat di pahami oleh penggunanya. 


\section{DAFTAR PUSTAKA}

[1].Application Fundamentals. Android Developers. 2012. Android, Inc. 22 September 2012.

[2].Chamidah Atien Nur, Deteksi Dini Gangguan Pertumbuhan dan Perkembangan Anak, Jurnal pertumbuhan Anak, Vol 10 No 3, Maret 2015.

[3].Diana, Fivi Melva, 2010. Pemantauan Perkembangan Anak Balita, Jurnal Kesehatan Masyarakat, Vol 04 No 02. September 2010.

[4]. Martono, Kridalukmana, 2014. Mobile Augmented Reality Jurusan Sistem Komputer Universitas Diponegoro Berbasis Android, (MARSISKOM). Jurnal Sistem Komputer, volume 4, nomor 1

[5]. Satria Hernanda, Wiyli Yustanti, etc, 2016, Rancang Bangun Aplikasi Monitoring Tumbuh Kembang Balita Berbasis Android. Jurnal Managemen Informatika, Vol 6 No 1.

[6]. Suyitno, H, dan Narendra, 2003. Pertumbuhan Fisik Anak, Jakarta. EGC 